\title{
UroVysion fluorescence in situ hybridization in urothelial carcinoma: a narrative review and future perspectives
}

\author{
Takashi Nagai ${ }^{1}$, Taku Naiki ${ }^{1}$, Toshiki Etani $^{1}$, Keitaro Iida ${ }^{1}$, Yusuke Noda ${ }^{1}$, Nobuhiko Shimizu ${ }^{1}$, \\ Teruki Isobe ${ }^{1}$, Satoshi Nozaki ${ }^{1}$, Takehiko Okamura ${ }^{2}$, Ryosuke Ando ${ }^{1}$, Noriyasu Kawai ${ }^{1}$, Takahiro Yasui ${ }^{1}$ \\ ${ }^{1}$ Department of Nephro-urology, Nagoya City University, Graduate School of Medical Sciences, Nagoya, Japan; ${ }^{2}$ Department of Urology, Anjo \\ Kosei Hospital, Anjo City, Japan \\ Contributions: (I) Conception and design: T Nagai, T Naiki, T Okamura, T Yasui; (II) Administrative support: All authors; (III) Provision of \\ study materials or patients: T Etani, K Iida; (IV) Collection and assembly of data: Y Noda, N Shimizu, T Isobe, S Nozaki; (V) Data analysis and \\ interpretation: R Ando, N Kawai; (VI) Manuscript writing: All authors; (VII) Final approval of manuscript: All authors. \\ Correspondence to: Taku Naiki, MD, PhD. Department of Nephro-urology, Nagoya City University, Graduate School of Medical Sciences, Kawasumi 1, \\ Mizuho-cho, Mizuho-ku 467-8601, Nagoya, Japan. Email: naiki@med.nagoya-cu.ac.jp.
}

\begin{abstract}
The number of patients with urothelial carcinoma (UC) is high, with a corresponding demand for detecting UC easily and non-invasively. Cystoscopy and urine cytology, with widely known diagnostic accuracies, are the gold standards for identifying UC originating from the bladder. However, cystoscopy or other tests, such as ureteroscopy or retrograde pyelography, are uncomfortable for patients. Tests for urinary biomarkers are expected to satisfy the demand for less invasive tests that will benefit patients with anxiety for invasive tests such as cystoscopy or ureteroscopy. Although several urinary biomarkers have been reported to support the diagnosis or follow-up of UC, their use in the clinic is uncommon. The UroVysion test examines urinary biomarkers using a multitarget, multicolor fluorescence in situ hybridization (FISH) assay. The test uses exfoliated cells found in urine and is a mixture of centromeric fluorescent denatured chromosome enumeration probes for chromosomes 3, 7, and 17 (labelled stratum red, spectrum green and spectrum aqua, respectively), and a locus-specific identifier probe for 9p21 (spectrum gold). It is used for the initial diagnosis of patients with hematuria or the monitoring of patients previously diagnosed with bladder cancer. Almost 20 years have passed since UroVysion was approved by the U.S. Food and Drug Administration, and so this is a well-established test. However, room exists for further research, with numerous reports on this test having been recently published. In order to update our knowledge, we herein present a brief overview of UroVysion and its features that follows the latest findings as they relate to UC.
\end{abstract}

Keywords: UroVysion; urothelial cancer; fluorescence in situ hybridization (FISH)

Submitted Aug 28, 2020. Accepted for publication Dec 08, 2020.

doi: $10.21037 /$ tau-20-1207

View this article at: http://dx.doi.org/10.21037/tau-20-1207

\section{Introduction}

Urothelial carcinoma (UC) develops in either the upper (pyelocaliceal cavities and ureter) or lower (bladder and urethra) portions of the urinary tract. As the 10th most common cancer worldwide, approximately 550,000 cases of bladder cancer (BCa) are newly diagnosed annually (1).
Although upper urinary tract carcinoma is an uncommon carcinoma, it accounts for $5-10 \%$ of all UCs (2). Generally, patients with UC complain of gross hematuria. The standard diagnostic tools available for the detection of $\mathrm{BCa}$ are cystoscopy, ureteroscopy, ultrasonography, and urine cytology. Magnetic resonance imaging and

^ ORCID: 0000-0002-7638-6048. 


\begin{tabular}{cccc}
\hline Fluorophore & Chromosome & Cytogenic location & Probe name \\
\hline 0 & 3 & 3p11.1-q11.1 Alpha Satellite DNA & Vysis CEP3 SpectrumRed \\
0 & 7 & 7p11.1-q11.1 Alpha Satellite DNA & Vysis CEP7 SpectrumGreen \\
$\bigcirc$ & 9 & $9 p 21$ & Vysis LSI p16 (9p21) SpectrumGold Probe \\
& 17 & 17p11.1-q11.1 Alpha Satellite DNA & CEP 17 SpectrumAqua \\
\hline
\end{tabular}

Figure 1 Details of fluorescence in situ hybridization (FISH) probes.

computed tomography are also used for staging. Retrograde pyelography is used for detecting ureteral or renal pelvic UCs. However, cystoscopy, including retrograde pyelography, is reported as being uncomfortable for patients (3). Moreover, it is difficult to detect small, flat carcinomas using the aforementioned techniques. For the differential diagnosis of hematuria and the follow-up of urothelial cancers, a noninvasive, highly accurate test is therefore required.

The measurement of urinary biomarkers is one method of examining patients for UCs. Its simplicity of use and noninvasiveness meet the needs of both physicians and patients. To date, tests involving several urinary biomarkers are in clinical use: CxBladder (Pacific edge Ltd., Dunedin, New Zealand), bladder tumor-associated antigen (BTA; Polymedco Inc., Cortlandt Manor, NY, USA), Immnocyt/uCyt+ (Diagnocure, Inc., Quebec City, Canada), nuclear matrix protein 22 (NMP22; Matritech. Inc., Newton, MA, USA), AssureMDx (MDxHealth, Irvine, CA, USA), and UroVysion (Abbott Molecular Inc., Des Plaines, Il., USA). These have all been approved by the U.S. Food and Drug Administration (FDA) as non-invasive tests to diagnose $\mathrm{BCa}$ (4). They have also supported the diagnosis of UC or are used for follow-up (5).

The UroVysion test for urinary biomarkers is made up of a multitarget, multicolor fluorescence in situ hybridization (FISH) assay (6). One of the features of this test is its dependence on specific chromosomal abnormalities occurring in high numbers in urothelial cancers (7). The use of several probes in this assay means an improvement in sensitivity compared to using single probes (6). The test is performed on exfoliated cells in urine using centromeric fluorescent denatured chromosome enumeration probes for chromosomes 3, 7, and 17 (stratum red, spectrum green, and spectrum aqua, respectively), and a locus-specific identifier probe for 9p21 (spectrum gold), with a high sensitivity for detecting carcinomas (8). The details of each probe are outlined in Figure 1. Indications for UroVysion analysis in urinary cytology include: atypical urinary cytology, for control after intravesical Bacillus Calmette-Guérin (BCG) treatment, atypical upper urinary tract cytology, followup after transurethral resection, and hematuria in patients with increased risk of UC (9). This test was approved by the FDA in 2001 and has been used to diagnose the recurrence of BCa from 2001 and to examine gross hematuria from 2005. In addition, it has been suggested that UroVysion FISH be used to judge the response to intravesical BCG therapy and in adjudicated equivocal cytology in American Urological Association guidelines (level of recommendation: expert opinion). UroVysion is also described as a potential urinary biomarker for the detection of invisible tumors in European Association of Urology guidelines. In National Comprehensive Cancer Network guidelines, UroVysion or NMP22 are considered markers useful in monitoring the recurrence of $\mathrm{BCa}$. However, though the various guidelines described above highlight the usefulness of UroVysion, it is necessary to recognize variations in its use with regard to clinical settings.

Indeed, the use of UroVysion have not changed significantly in recent years. However, the treatment of UC has gradually improved due to the appearance of new therapies such as molecular-targeted drugs or a combination of intravesical therapy and immune-oncology drugs. Genetic mutations are therapeutic targets and screening for these seems to be required to achieve tailor-made therapy. A method that detects genetic mutations in urine samples using FISH can change the future treatment of UC. We present the following article in accordance with the Narrative Review reporting checklist (available at http:// dx.doi.org/10.21037/tau-20-1207).

\section{Methods}

A literature review in English was conducted using PubMed 


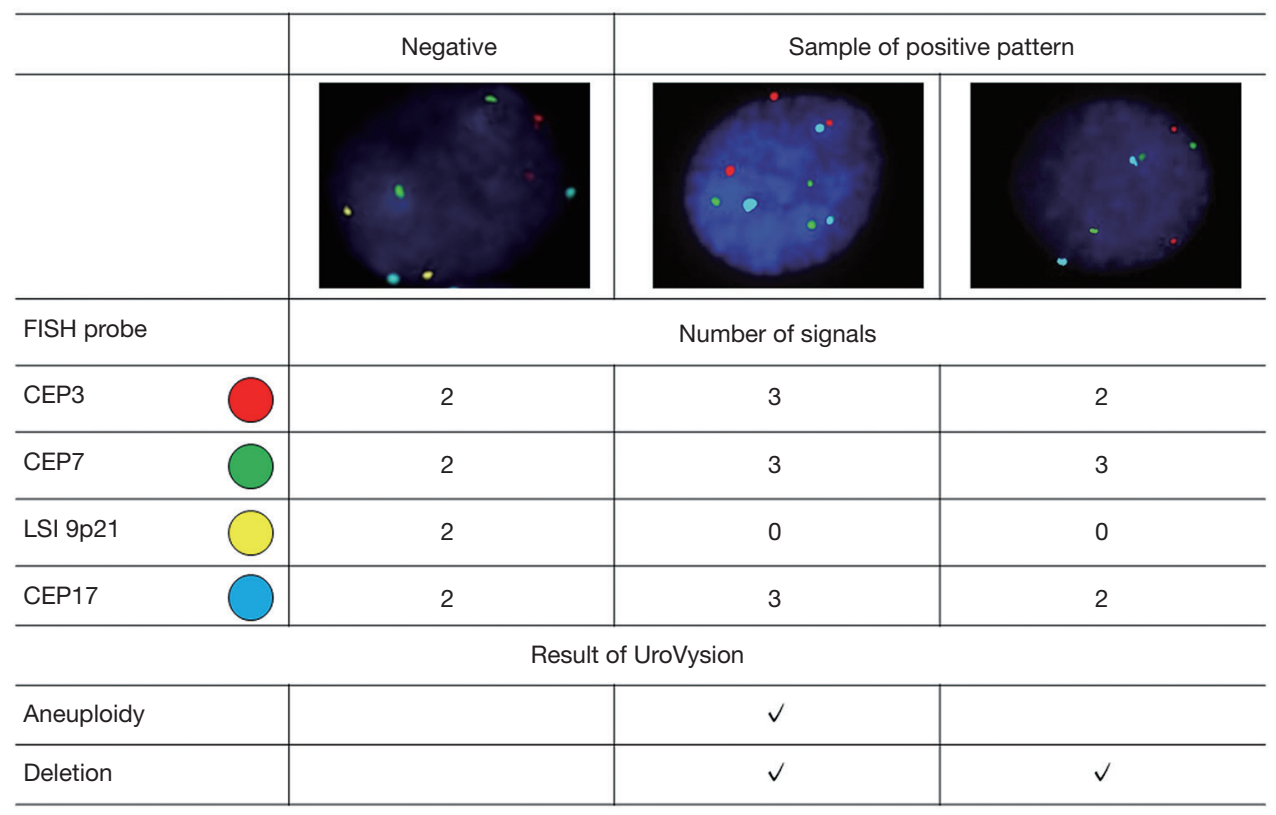

Figure 2 Patterns of fluorescence in situ hybridization (FISH) signals.

and Google Scholar databases up to September 2020. Search terms included: "UroVysion" AND "urology" or "FISH" AND "urology". The studies were reviewed by three authors to assess whether they were appropriate.

\section{What is FISH and UroVysion?}

Genetic abnormalities, including mutations and chromosome and gene copy number irregularities, drive the development and progression of cancer (9). FISH is a method to detect genetic alterations by hybridizing such genes with oligonucleotide probes labeled with a fluorescent substance or an enzyme to identify the target using a fluorescence microscope. FISH is widely used for detecting chromosomal abnormalities in various cancers. Moreover, it is thought to be an objective examination since it clearly detects a specific gene locus compared to conventional pathological examinations.

UroVysion is a molecular cytology test for BCa that uses FISH for the detection of aneuploidy in chromosomes 3, 7 , and 17 , and the loss of the 9p21 locus. The four probes are used in response to the increased copy numbers of chromosomes 3, 7, and 17 found in BCa as well as the deletion of $9 \mathrm{p} 21$, where P16, the tumor suppressor gene, resides (9). UroVysion is assessed by measuring the number of fluorescent signals in at least 25 cells that show an abnormal morphology. According to the manufacturer's criteria, the chromosome pattern needs to be recorded only if (I) there is a gain (i.e., three or more signals) of more than two of chromosomes 3,7 , or 17 , or (II) if both copies of LSI 9 p2 1 are absent. The test is positive if there has been an increase of four or more cells showing multiple chromosomes or more than 12 cells that have lost a 9p21 signal. The negative signal pattern and some of positive signal patterns are shown in Figure 2.

Although it appears to be an objective examination compared to urine cytology, UroVysion results sometimes depend on the skill of the laboratory technicians who perform the test. Moreover, UroVysion analysis should be conducted by well-experienced laboratory technicians in cytopathology (10). This is because the interpretation of UroVysion may be difficult due to the use of fluorescence (6). Physicians should also interpret UroVysion results with regard to clinical findings and not leave examinations to laboratory technicians.

Surveillance with the UroVysion can provide prognostic information for patients with non-muscle invasive UC (11); however, it is crucial to consider the patient's background in order to attain an accurate diagnosis. Results may vary with regard to sensitivity and specificity, which might be due to selection bias of patients. UroVysion and urine cytology are not thought to be affected by the presence of erythrocytes or leukocytes compared to the NMP22 test (12). However, 
the UroVysion test yields false positives due to the presence of umbrella cells, as suggested by the presence of chromosome tetraploidy, or heteroploidy, which appears because of human polyomavirus infection (13-15).

Most papers have compared the UroVysion test to urine cytology or other urinary biomarkers. However, comparisons are difficult simply because of the variations in clinical settings. We have reviewed previous reports based on each clinical setting.

\section{Screening hematuria}

Hematuria is one of the major complaints of UC including BCa. Generally, urine cytology is conducted to diagnose urinary tract cancers or in a work-up of hematuria. The definitive role of urinary biomarkers is yet to be established. However, a recent meta-analysis of urinary biomarkers for the evaluation of primary hematuria concluded that evidence for the use of urinary biomarkers was limited with regard to diagnostic performance, casting doubt on the routine use of these instead of cystoscopy (4).

Few reports exist regarding the evaluation of hematuria by UroVysion. UroVysion has been described as an accurate, more sensitive test than voided cytology, and has been used to detect $\mathrm{BCa}$ in patients showing gross or microscopic hematuria of all stages and grades (16). The UroVysion test detected $69 \%$ of UCs while cytology detected 38\%; the gap between these widened if low-grade, low-stage tumors were excluded (16). Based on these data, the FDA approved UroVysion for examining hematuria from 2005.

\section{$\mathrm{BCa}$}

Lists of major studies that compared UroVysion and urine cytology are shown in Table 1.

In a meta-analysis, Hajdinjak (2008) reported the superiority of UroVysion to urine cytology, showing a sensitivity of $72 \%$ and specificity of $84 \%$ compared with $42 \%$ and $96 \%$ for cytology, respectively (24). However, such differences disappeared when superficial cases were excluded (24). Several conflicting reports exist with regard to the diagnosing power of UroVysion. In a surveillance of non-muscle invasive $\mathrm{BCa}$, UroVysion did not yield urine cytology for the detection of visible BCa (25). In Japanese reports, a similar study reported that UroVysion alone was insufficient for detecting BCa (26).

Combining UroVysion and urine cytology was reported as a method to improve sensitivity $(25,26)$. Daniely et al. (2007) reported on the utility of urine cytology and UroVysion by using an automated microscope (27). Kojima et al. (2018) described the usefulness of a consecutive UroVysion test: Two consecutive positive UroVysion test results led to a cancer detection rate of $14.8 \%$, which was greater than a positive result in either $(7.2 \%)$ or neither $(1.2 \%)$ of the two tests for patients at a 3-month follow-up (28).

However, several clinical situations have led to suspicious urine cytology results. Ferra et al. (2009) reported that a negative UroVysion result did not exclude the presence of high-grade UC (29). However, a recent prospective study showed the utility of UroVysion in a comparison to urine cytology in terms of sensitivity and specificity, and recommended the use of UroVysion in case of a suspicious result in urine cytology (30).

The interpretation of a 9p21 loss differs in several reports. Zellweger (2006) reported that the presence of a 9p21 deletion was significantly associated with recurrence (13). However, in a prospective study of 1,595 male chemical workers, a loss of 9p21 was less predictive for detecting $\mathrm{BCa}$ because of a clinical setting in which few low-grade cancers existed (31).

\section{UC of upper urinary tract}

Ureteroscopy is a major tool for the diagnosis of upper tract UC. However, concerns exist because of its invasiveness, which may lead to severe complications such as bleeding, ureteral perforation, or stripping of the ureter (32). Compared to those of urine cytology, the sensitivity and specificity of UroVysion was significantly higher $(76.7 \%$ vs. $36 \%$ and $94.7 \%$ vs. $100 \%$, respectively (33). A multicentre cohort study found a higher diagnosing accuracy for UroVysion in UC (34). The overall sensitivity of UroVysion was higher than that of the cytology (100\% vs. 20.8\%), with the specificity $89.5 \%$ for UroVysion and $97.4 \%$ for cytology (34). Freund et al. (2019) reported that using UroVysion for $1 \mathrm{~mL}$ of passively collected upper tract urine in detecting upper urinary tract $\mathrm{UC}$ was feasible, even if the sample size used was small (35). Compared to negative results, positive FISH results predicted more advanced tumor stages and higher tumor grades (36). In addition, UroVysion was also reported to improve diagnostic accuracy for UC of the upper urinary tract when combined with urine cytology $(37,38)$.

Conflicting opinions exist with regard to using UroVysion for the surveillance of upper tract UC. Fernández et al. (2012) examined the utility of UroVysion 


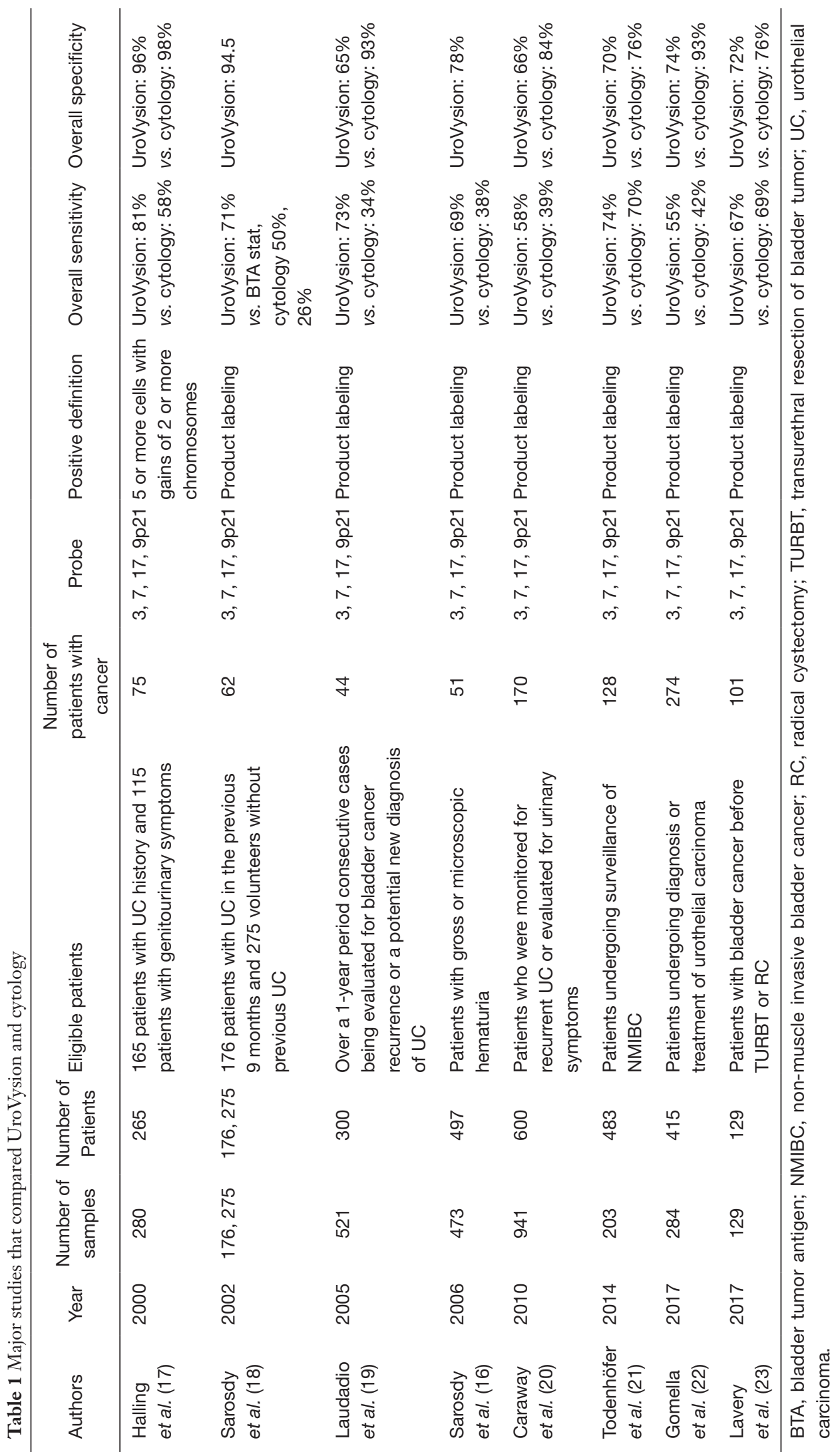


to detect upper tract UC in the follow-up of patients after cystectomy and concluded it was not suitable (39).

In summary, the sensitivity of UroVysion appears higher than that of urine cytology for diagnosing upper tract UC but indications for its routine use have not been established.

\section{Monitoring as follow-up}

\section{BCa surveillance without visible tumors}

Several reports exist of the usefulness of UroVysion in predicting BCa recurrence and progression. Yoder et al. (2007) reported a prospective study of patients under surveillance for BCa where recurrence was not shown. For $65 \%$ of a UroVysion-positive group, UC originated from bladder recurred within 29 months (40). Sarosdy et al. (2002) compared the predictive power of $\mathrm{BCa}$ recurrence between FISH, a BTA stat test, and cytology, and concluded overall sensitivities were $71 \%$ for FISH, $50 \%$ for the BTA stat test, and $26 \%$ for cytology (18). Seideman et al. (2015) also reported that in patients with a positive FISH result, BCa was more likely to recur regardless of a visible tumor (41). Kim et al. (2014) reported that being UroVysion-positive could predict the recurrence and progression of $\mathrm{BCa}$ in patients with negative cystoscopy and suspicious cytology results, and in those with a non-muscle invasive BCa negative result by cystoscopy (42). A prospective study comparing urinary biomarkers in a followup of patients with non-muscle invasive $\mathrm{BCa}$ with a low grade highlighted the superiority of UroVysion to cytology in terms of sensitivity and specificity (43). Consecutive UroVysion testing was reported as a more reliable method in predicting intravesical recurrence after transurethral resection of bladder tumor (TURBT) (15). In addition, these circumstances might change in the era of high-resolution endoscopes such as narrow band imaging or photodynamic diagnosis (15).

\section{BCa surveillance after intravesical therapy}

UroVysion is also reported as a useful predictive test for anticipating $\mathrm{BCa}$ recurrence after intravesical therapy. Kipp et al. (2005) reported that monitoring using UroVysion was useful for predicting the progression of BCa to becoming muscle invasive in patients with intravesical therapy, including BCG and other intravesical therapies (44). Whitson et al. (2009) reported a UroVysion positive test after intravesical treatment was highly predictive of recurrence in a retrospective study (45). Regarding BCG intravesical treatment, Mengual et al. (2007) suggested that a UroVysion result was useful for judging the need for adjuvant therapy in patients with a high-risk superficial $\mathrm{BCa}$ after an initial transurethral resection (46). Kamat et al. (2012) also reported a correlation between UroVysion results and the recurrence of BCa after BCG intravesical therapy; the timing of a positive test was important to predict recurrence (47). Freund et al. (2019) reported a significant correlation of recurrence in patients with intermediate- and high-risk $\mathrm{UC}$ originated from the bladder after intravesical BCG therapy and a positive UroVysion test 3 months following TURBT (35). A recent prospective, multicenter diagnostic trial followed previous results showing that a UroVysion positive result indicated a risk of recurrence (48). Though many studies suggest the effectiveness of a UroVysion test as a marker of $\mathrm{BCa}$ recurrence, some studies suggest the contrary. Savic et al. (2009) reported that a UroVysion test was superior to urine cytology only in the cases except for unequivocally positive cytology (49). They also concluded that a UroVysion test does not yield further information on clearly malignant cytology (49).

\section{Modification of UroVysion}

Some studies tried to achieve better diagnostic accuracy than conventional UroVysion tests. Kipp et al. (2009) described the utility of counting abnormal cells, with the percentage of these a predictor of cancer recurrence and progression (50). Ferra et al. (2009) reported that less strict criteria dramatically improved the sensitivity of UroVysion instead of decreasing its specificity (29). The degree of chromosomal abnormalities, detected and assessed quantitatively by UroVysion, was reported as a predictor of the progression of non-muscle-invasive into muscle-invasive BCa (51). Ho et al. (2013) reported that specificity was improved by excluding chromosome 9 deletion; the use of UroVysion may allow the conservation of health resources and minimize trauma in patients by avoiding cystoscopy (52). Zhou et al. (2016) focused on tetrasomy and insisted this was a nonspecific finding that was frequently encountered and should be excluded from a polysomy classification (53). However, each study requires further investigation due to the small sample sizes used.

\section{Cost effectiveness of UroVysion}

The costs associated with treating patients with $\mathrm{BCa}$ is highest among all cancers due to the monitoring and treatment required (54). The cost of diagnostic strategy in 
$\mathrm{BCa}$ is expected to increase because of the arrival of new modalities. Physicians need to consider the cost effectiveness of each modality. The UroVysion test is a reasonable test for detecting BCa but shared positive test with urine cytology, which is a much cheaper test; its role is still questionable with regard to cost $(29,31)$. Due to its high-cost limits and the fact that it is time consuming for use as a screening tool, a UroVysion test is not cost-effective (55). Kamat et al. (2011) examined the cost-effectiveness of using cystoscopy, in addition to urine cytology and urinary biomarkers, in their prospective study (56). They concluded that the cost per tumor detected using cystoscopy and UroVysion was much greater than that of cystoscopy on its own $(\$ 19,111$ $v s . \$ 7,692)$ in following up of $\mathrm{BCa}$; the addition of urinary biomarkers did not improve the detection of invasive disease. In another study, some experts were against using UroVysion in screening for hematuria due to its low costeffectiveness and it being time-consuming $(10,57,58)$.

\section{The role of UroVysion in the era of diagnosis based on The Paris System on Reporting Urinary Cytology (TPS) since 2016}

For the long time, there was no standard diagnostic criteria of atypical urothelial cells universally available across different international institutions. For resolving this problem, TPS was proposed for pathological criteria using defined cytomorphologic classification for the diagnosis of urine cytology, and has been gradually prevailed. So far, several reports described that TPS could improve the reliability and accuracy of interpretations especially in urine cytology for high grade UC (HGUC). Based on the tendency, the number of articles presenting as to the efficacy of UroVysion using TPS. Miki et al. (2017) reviewed the UroVysion testing cases over a period of 6 years, and reclassified according to TPS, and reported that the sensitivity and specificity of UroVysion were $62.5 \%$ and $100 \%$ in the negative for HGUC groups (59). Recently, Tian et al. (2020) chronologically reviewed and retrospectively compared urine cytology diagnoses between pre-TPS and post-TPS, and described that all categories in urine cytology had superior correlation with UroVysion results by post-TPS, and positive UroVysion results increased from $87 \%$ to $93 \%$ in suspicious for HGUC category. By these results, it is hopeful that application of TPS could lead to significant reduction of atypical UC diagnosis, and potential cost effectiveness (60).

\section{Future perspectives on UroVysion}

Recent advances in searching for genetic mutations have led to a paradigm shift in the treatment of cancers. In the case of observing genetic mutations in cells from urine samples, UroVysion has an important role to play in improving the management of cancer, especially UC. Several reports describe comparing or combining UroVysion with another type of genetic examination. Montalbo et al. (2020) reported that the sensitivities of UroVysion, the mutation analysis of fibroblast growth factor receptor 3 and telomerase reverse transcriptase, and urine-based gene expression analysis in the case of high-grade tumors were comparable but higher than that of cytology according to the Paris System for reporting urinary cytology reclassification (30). Chen et al. (2020) focused on urine DNA methylation to improve the sensitivity of detecting particularly low-grade and early-stage BCas compared with using cytology and UroVysion (61). Various urine-based examinations, including for genetic mutations, have been reported for decades but have not been found to be superior to UroVysion in detecting UC. Combining new types of examinations with UroVysion or using tailormade examinations with various urine-based biomarkers are envisioned.

\section{Limitations}

This narrative review has several limitations. First, quantitative analyses of the included studies were not conducted. Since the background of each study differs, differences in data between these studies need to be assessed statistically. Second, the inclusion/exclusion criteria used for the literature reviewed were ambiguous. To maintain the validity of the review, multiple authors were used to assess whether to include each article for this review.

\section{Conclusions}

The accuracy of UroVysion tests can improve the diagnosis of UCs. Though various indications need to be considered by physicians when using UroVysion, cost concerns arise when this test is used blindly for screening the recurrence of UC. UroVysion has the potential to detect genetic mutations in cells from urine samples. Novel ways of improving or combining other types of pathological examinations with UroVysion are expected to provide new diagnostic tools in the treatment of UC. 


\section{Acknowledgments}

Funding: None.

\section{Footnote}

Provenance and Peer Review: This article was commissioned by the Guest Editor (Kazutoshi Fujita) for the series "Urinary Biomarkers of Urothelial Malignancies" published in Translational Andrology and Urology. The article has undergone external peer review.

Reporting Checklist: The authors have completed the Narrative Review reporting checklist. Available at http:// dx.doi.org/10.21037/tau-20-1207

Conflicts of Interest: All authors have completed the ICMJE uniform disclosure form (available at http:// dx.doi.org/10.21037/tau-20-1207). The series "Urinary Biomarkers of Urothelial Malignancies" was commissioned by the editorial office without any funding or sponsorship. The authors have no other conflicts of interest to declare.

Ethical Statement: the authors are accountable for all aspects of the work in ensuring that questions related to the accuracy or integrity of any part of the work are appropriately investigated and resolved.

Open Access Statement: This is an Open Access article distributed in accordance with the Creative Commons Attribution-NonCommercial-NoDerivs 4.0 International License (CC BY-NC-ND 4.0), which permits the noncommercial replication and distribution of the article with the strict proviso that no changes or edits are made and the original work is properly cited (including links to both the formal publication through the relevant DOI and the license). See: https://creativecommons.org/licenses/by-nc-nd/4.0/.

\section{References}

1. Richters A, Aben KKH, Kiemeney LALM. The global burden of urinary bladder cancer: an update. World J Urol 2020;38:1895-904.

2. Soria F, Shariat SF, Lerner SP, et al. Epidemiology, diagnosis, preoperative evaluation and prognostic assessment of upper-tract urothelial carcinoma (UTUC). World J Urol 2017;35:379-87.

3. Seklehner S, Remzi M, Fajkovic H, et al. Prospective
Multi-institutional Study Analyzing Pain Perception of Flexible and Rigid Cystoscopy in Men. Urology 2015;85:737-41.

4. Sathianathen NJ, Butaney M, Weight CJ, et al. Urinary Biomarkers in the Evaluation of Primary Hematuria: A Systematic Review and Meta-Analysis. Bladder Cancer 2018;4:353-63.

5. Bhat A, Ritch CR. Urinary biomarkers in bladder cancer: Where do we stand? Curr Opin Urol 2019;29:203-9.

6. Têtu B. Diagnosis of urothelial carcinoma from urine. Mod Pathol 2009;22:S53-9.

7. Lokeshwar VB, Habuchi T, Grossman HB, et al. Bladder tumor markers beyond cytology: International Consensus Panel on bladder tumor markers. Urology 2005;66:35-63.

8. Sokolova IA, Halling KC, Jenkins RB, et al. The development of a multitarget, multicolor fluorescence in situ hybridization assay for the detection of urothelial carcinoma in Urine. J Mol Diagn 2000;2:116-23.

9. Bubendorf L. Multiprobe fluorescence in situ hybridization (UroVysion) for the detection of urothelial carcinoma FISHing for the right catch. Acta Cytol 2011;55:113-9.

10. Bubendorf L, Piaton E. UroVysion ${ }^{\circledR}$ multiprobe FISH in the triage of equivocal urinary cytology cases. Ann Pathol 2012;32:e52-6, 438-43.

11. Miyake M, Owari T, Hori S, et al. Emerging biomarkers for the diagnosis and monitoring of urothelial carcinoma. Res Rep Urol 2018;10:251-61.

12. Pesch B, Taeger D, Johnen G, et al. Screening for bladder cancer with urinary tumor markers in chemical workers with exposure to aromatic amines. Int Arch Occup Environ Health 2014;87:715-24.

13. Zellweger T, Benz G, Cathomas G, et al. Multi-target fluorescence in situ hybridization in bladder washings for prediction of recurrent bladder cancer. Int J Cancer 2006;119:1660-5.

14. Kipp BR, Sebo TJ, Griffin MD, et al. Analysis of Polyomavirus-Infected Renal Transplant Recipients' Urine Specimens. Am J Clin Pathol 2005;124:854-61.

15. Ikeda A, Kojima T, Kawai K, et al. Risk for intravesical recurrence of bladder cancer stratified by the results on two consecutive UroVysion fluorescence in situ hybridization tests: a prospective follow-up study in Japan. Int J Clin Oncol 2020;25:1163-9.

16. Sarosdy MF, Kahn PR, Ziffer MD, et al. Use of a Multitarget Fluorescence In Situ Hybridization Assay to Diagnose Bladder Cancer in Patients With Hematuria. J Urol 2006;176:44-7.

17. Halling KC, King W, Sokolova IA, et al. A comparison 
of cytology and fluorescence in situ hybridization for the detection of urothelial carcinoma. J Urol 2000;164:1768-75.

18. Sarosdy MF, Schellhammer P, Bokinsky G, et al. Clinical evaluation of a multi-target fluorescent in situ hybridization assay for detection of bladder cancer. J Urol 2002;168:1950-4

19. Laudadio J, Keane TE, Reeves HM, et al. Fluorescence in situ hybridization for detecting transitional cell carcinoma: implications for clinical practice. BJU Int 2005;96:1280-5.

20. Caraway NP, Khanna A, Fernandez RL, et al. Fluorescence in situ hybridization for detecting urothelial carcinoma: a clinicopathologic study. Cancer Cytopathol 2010;118:259-68.

21. Todenhöfer T, Hennenlotter J, Esser M, et al. Stepwise application of urine markers to detect tumor recurrence in patients undergoing surveillance for non-muscle-invasive bladder cancer. Dis Markers 2014;2014:973406.

22. Gomella LG, Mann MJ, Cleary RC, et al. Fluorescence in situ hybridization (FISH) in the diagnosis of bladder and upper tract urothelial carcinoma: the largest singleinstitution experience to date. Can J Urol 2017;24:8620-6.

23. Lavery HJ, Zaharieva B, McFaddin A, et al. A prospective comparison of UroVysion FISH and urine cytology in bladder cancer detection. BMC Cancer 2017;17:247.

24. Hajdinjak T. UroVysion FISH test for detecting urothelial cancers: Meta-analysis of diagnostic accuracy and comparison with urinary cytology testing. Urol Oncol 2008;26:646-51.

25. Moonen PMJ, Merkx GFM, Peelen P, et al. UroVysion Compared with Cytology and Quantitative Cytology in the Surveillance of Non-Muscle-Invasive Bladder Cancer. Eur Urol 2007;51:1275-80.

26. Nagai T, Okamura T, Yanase T, et al. Examination of diagnostic accuracy of UroVysion fluorescence in situ hybridization for bladder cancer in a single community of Japanese hospital patients. Asian Pac J Cancer Prev 2019;20:1271-3.

27. Daniely M, Rona R, Kaplan T, et al. Combined morphologic and fluorescence in situ hybridization analysis of voided urine samples for the detection and follow-up of bladder cancer in patients with benign urine cytology. Cancer 2007;111:517-24.

28. Kojima T, Nishiyama H, Ozono S, et al. Clinical evaluation of two consecutive UroVysion fluorescence in situ hybridization tests to detect intravesical recurrence of bladder cancer: a prospective blinded comparative study in Japan. Int J Clin Oncol 2018;23:1140-7.

29. Ferra S, Denley R, Herr H, et al. Reflex UroVysion testing in suspicious urine cytology cases. Cancer 2009;117:7-14.
30. Montalbo R, Izquierdo L, Ingelmo-Torres M, et al. Urine cytology suspicious for urothelial carcinoma: Prospective follow-up of cases using cytology and urine biomarker-based ancillary techniques. Cancer Cytopathol 2020;128:460-9.

31. Bonberg N, Taeger D, Gawrych K, et al. Chromosomal instability and bladder cancer: the UroVysion(TM) test in the UroScreen study. BJU Int 2013;112:E372-E382.

32. Yu J, Xiong H, Wei C, et al. Utility of fluorescence in situ hybridization analysis for detecting upper urinary tracturothelial carcinoma. J Cancer Res Ther 2017;13:647.

33. Marín-Aguilera M, Mengual L, Ribal MJ, et al. Utility of Fluorescence In Situ Hybridization as a Non-invasive Technique in the Diagnosis of Upper Urinary Tract Urothelial Carcinoma. Eur Urol 2007;51:409-15.

34. Mian C, Mazzoleni G, Vikoler S, et al. Fluorescence in situ hybridisation in the diagnosis of upper urinary tract tumours. Eur Urol 2010;58:288-92.

35. Freund JE, Liem EIML, Savci-Heijink CD, et al. Fluorescence in situ hybridization in $1 \mathrm{~mL}$ of selective urine for the detection of upper tract urothelial carcinoma: a feasibility study. Med Oncol 2018;36:10.

36. Su X, Hao H, Li X, et al. Fluorescence in situ hybridization status of voided urine predicts invasive and high-grade upper tract urothelial carcinoma. Oncotarget 2017;8:26106-11.

37. Todenhöfer T, Hennenlotter J, Esser M, et al. Combined application of cytology and molecular urine markers to improve the detection of urothelial carcinoma. Cancer Cytopathol 2013;121:252-60.

38. Sassa N, Iwata H, Kato M, et al. Diagnostic Utility of UroVysion Combined With Conventional Urinary Cytology for Urothelial Carcinoma of the Upper Urinary Tract. Am J Clin Pathol 2019;151:469-78.

39. Fernández MI, Parikh S, Grossman HB, et al. The role of FISH and cytology in upper urinary tract surveillance after radical cystectomy for bladder cancer. Urol Oncol 2012;30:821-4.

40. Yoder BJ, Skacel M, Hedgepeth R, et al. Reflex UroVysion testing of bladder cancer surveillance patients with equivocal or negative urine cytology: A prospective study with focus on the natural history of anticipatory positive findings. Am J Clin Pathol 2007;127:295-301.

41. Seideman C, Canter D, Kim P, et al. Multicenter evaluation of the role of UroVysion FISH assay in surveillance of patients with bladder cancer: does FISH positivity anticipate recurrence? World J Urol 2015;33:1309-13. 
42. Kim PH, Sukhu R, Cordon BH, et al. Reflex fluorescence in situ hybridization assay for suspicious urinary cytology in patients with bladder cancer with negative surveillance cystoscopy. BJU Int 2014;114:354-9.

43. Benderska-Söder N, Hovanec J, Pesch B, et al. Toward noninvasive follow-up of low-risk bladder cancer Rationale and concept of the UroFollow trial. Urol Oncol 2020;38:886-95.

44. Kipp BR, Karnes RJ, Brankley SM, et al. Monitoring intravesical therapy for superficial bladder cancer using fluorescence in situ hybridization. J Urol 2005;173:401-4.

45. Whitson J, Berry A, Carroll P, et al. A multicolour fluorescence in situ hybridization test predicts recurrence in patients with high-risk superficial bladder tumours undergoing intravesical therapy. BJU Int 2009;104:336-9.

46. Mengual L, Marín-Aguilera M, José Ribal M, et al. Clinical Utility of Fluorescent in situ Hybridization for the Surveillance of Bladder Cancer Patients Treated with Bacillus Calmette-Gué rin Therapy. Eur Urol 2007;52:752-9.

47. Kamat AM, Dickstein RJ, Messetti F, et al. Use of fluorescence in situ hybridization to predict response to bacillus Calmette-Guérin therapy for bladder cancer: Results of a prospective trial. J Urol 2012;187:862-7.

48. Lotan Y, Inman BA, Davis LG, et al. Evaluation of the Fluorescence In Situ Hybridization Test to Predict Recurrence and/or Progression of Disease after bacillus Calmette-Guérin for Primary High Grade Nonmuscle Invasive Bladder Cancer: Results from a Prospective Multicenter Trial. J Urol 2019;202:920-6.

49. Savic S, Zlobec I, Thalmann GN, et al. The prognostic value of cytology and fluorescence in situ hybridization in the follow-up of nonmuscle-invasive bladder cancer after intravesical Bacillus Calmette-Guérin therapy. Int J Cancer 2009; 124:2899-904.

50. Kipp BR, Tanasescu M, Else TA, et al. Quantitative fluorescence in situ hybridization and its ability to predict bladder cancer recurrence and progression to muscleinvasive bladder cancer. J Mol Diagn 2009;11:148-54.

51. Kocsmár I, Pajor G, Gyöngyösi B, et al. Development

Cite this article as: Nagai T, Naiki T, Etani T, Iida K, Noda Y, Shimizu N, Isobe T, Nozaki S, Okamura T, Ando R, Kawai $\mathrm{N}$, Yasui T. UroVysion fluorescence in situ hybridization in urothelial carcinoma: a narrative review and future perspectives. Transl Androl Urol 2021;10(4):1908-1917. doi: 10.21037/tau-201207 and Initial Testing of a Modified UroVysion-Based Fluorescence In Situ Hybridization Score for Prediction of Progression in Bladder Cancer. Am J Clin Pathol 2020;153:274-84.

52. Ho CCK, Tan WP, Pathmanathan R, et al. Fluorescencein-situ-hybridization in the surveillance of urothelial cancers: Can use of cystoscopy or ureteroscopy be deferred? Asian Pac J Cancer Prev 2013;14:4057-9.

53. Zhou AG, Liu Y, St. Cyr M, et al. Role of tetrasomy for the diagnosis of urothelial carcinoma using UroVysion fluorescent in situ hybridization. Arch Pathol Lab Med 2016;140:552-9.

54. Botteman MF, Pashos CL, Redaelli A, et al. The Health Economics of Bladder Cancer: A Comprehensive Review of the Published Literature. Pharmacoeconomics 2003;21:1315-30.

55. Zhou AG, Owens CL, Cosar EF, et al. Clinical implications of current developments in genitourinary pathology. Arch Pathol Lab Med 2013;137:887-93.

56. Kamat AM, Karam JA, Grossman HB, et al. Prospective trial to identify optimal bladder cancer surveillance protocol: reducing costs while maximizing sensitivity. BJU Int 2011;108:1119-23.

57. Nieder AM, Soloway MS, Herr HW. Should We Abandon the FISH Test? European Urology 2007;51:1469-71.

58. Budman LI, Kassouf W, Steinberg JR. Biomarkers for detection and surveillance of bladder cancer. Can Urol Assoc J 2008;2:212-21.

59. Miki Y, Neat M, Chandra A. Application of The Paris System to atypical urine cytology samples: correlation with histology and UroVysion® FISH. Cytopathology 2017;28:88-95.

60. Tian W, Shore KT, Shah RB. Significant reduction of indeterminate (atypical) diagnosis after implementation of The Paris System for reporting urinary cytology: A single-institution study of more than 27,000 cases. Cancer Cytopathol 2021;129:114-20.

61. Chen X, Zhang J, Ruan W, et al. Urine DNA methylation assay enables early detection and recurrence monitoring for bladder cancer. J Clin Invest 2020;130:6278-89. 